\title{
Association between smoking and deaths due to colorectal malignant carcinoma: a national population-based case-control study in China
}

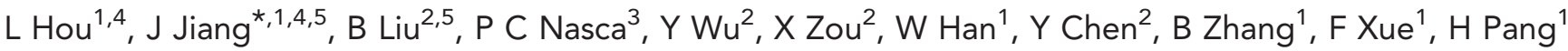 \\ and $\mathrm{J} \mathrm{Li}^{2}$
}

${ }^{1}$ Department of Epidemiology and Biostatistics, Institute of Basic Medical Sciences Chinese Academy of Medical Sciences/School of Basic Medicine Peking Union Medical College, Beijing, China; ${ }^{2}$ Cancer Institute \& Hospital, Chinese Academy of Medical Sciences/Peking Union Medical College, Beijing, China and ${ }^{3}$ School of Public Health, State University of New York, New York, NY, USA

Background: This study explored the association between smoking and colorectal malignant carcinoma (CRC) in the Chinese population at the national level for the first time.

Methods: In the China Nationwide Retrospective Mortality Survey conducted during 1989-1991, 12942 CRC cases among 1136336 all-cause deaths aged $\geqslant 30$ years were randomly assigned 25884 control interviews from 325255 surviving spouses of allcause deaths across 103 urban and rural areas.

Results: Compared with non-smokers, smoking significantly increased the risk of CRC-specific mortality by $9.8 \%$ (odds ratio $(O R)=1.098$, 95\% confidence interval $(C l)=1.046-1.153)$ adjusted for sex, age, and residence. There were significant doseresponse relationships between smoking and CRC, such as smoking years, cigarettes smoked daily, and age at onset of smoking. Long-term heavy smokers aged $\geqslant 50$ years with $\geqslant 30$ smoking years and $\geqslant 20$ cigarettes daily had an excess risk of CRC deaths of $30.2 \%(\mathrm{OR}=1.302,95 \% \mathrm{Cl}=1.214-1.397)$. The strongest association between these smoking variables, such as long-term heavy smokers (OR $=1.604,95 \% \mathrm{Cl}=1.341-1.919)$, and $\mathrm{CRC}$ was observed among rural men.

Conclusions: Quitting smoking at any time would likely be beneficial to CRC prevention. Long-term heavy smokers and rural men should be viewed as special targets for smoking prevention and cessation programs.

China has become the largest consumer of tobacco in the world with an estimated 301 million current smokers (Li et al, 2011). The tobacco control situation in China is worrisome owing to the influences of a powerful tobacco industry with the competition between tobacco control organisations, and the tobacco industry is becoming increasingly fierce (Yang, 2013). As one of the most important smoking-related diseases, cancer is the second leading cause of deaths in the Chinese population. In developed countries, tobacco control accounted for almost all of the declines in smoking-related cancer mortality rates as seen during the past four decades (Cavalli, 2013).

Colorectal malignant carcinoma (CRC) has become the third leading form of cancer incidence and the fifth leading cause of cancer mortality for Chinese people. CRC incidence and mortality rates have also increased at a faster pace than any other form of cancer in China, although the CRC incidence and mortality rates in China are still much lower compared with the rates in Western countries (Rozen et al, 2002). Furthermore, China has high

\footnotetext{
*Correspondence: Professors J Jiang and B Liu; Email: jingmeijiang238@hotmail.com or boqiliu@163.com

${ }^{4}$ These authors contributed equally to this work (joint first authors).

${ }^{5}$ Boqi Liu is the corresponding author who appoints Jingmei Jiang as his agent.
}

Received 15 October 2013; revised 16 December 2013; accepted 19 December 2013; published online 30 January 2014 
prevalence of smoking, which has been recognised as one of the risk factors of CRC in Western countries (Chao et al, 2000; Botteri et al, 2008; Kenfield et al, 2008; Liang et al, 2009). However, the association between smoking and CRC in the Chinese population is unclear, with a positive association observed in the much more developed Hong Kong and Singapore Chinese (Ho et al, 2004; Tsong et al, 2007), but not in the more representative Shanghai Chinese (Chen et al, 1997; Ji et al, 2002).

Therefore, for either tobacco control or CRC prevention, it is necessary to explore a possible association between smoking and CRC in China. The aim of the current study is to explore the evidence of an association between smoking and CRC deaths by using data of the China National Mortality Survey data set.

\section{MATERIALS AND METHODS}

National mortality survey data. We used a data set from the China Nationwide Retrospective Mortality Survey. The study base covers 67 million people and includes 1136336 all-cause deaths of individuals aged 30 years or older during the years 1986-1988. Among these total deaths, there were 802032 (70.6\%) deaths in 24 urban areas and 334304 (29.4\%) deaths in 79 rural counties, which were randomly chosen from over 2000 counties in China to be included in a survey of smoking patterns during 1989-1991. These 103 areas covered all the geographic and economic zones across China, with 34 provincial administrative regions. According to a traditional classification of zones, 28 provincial administrative regions included large populations belonging to the northern coastal zone, the northern inland zone, the southern coastal zone, and the southern inland zone, respectively (Figure 1). We obtained personal information, such as name, sex, age, and address, of all living or deceased residents living in the study areas from the local Population Administrative Offices (PAO). Approximately 90\% of all deaths in these areas were included in our data set. The underlying cause of each death was coded according to the World Health Organization's International Classification of Diseases, the 9th revision (ICD-9). Additional details on the China Nationwide Retrospective Mortality Survey were described elsewhere (Liu et al, 1998).

Recruitment of cases and controls. The specific methods used to recruit all cases and controls are shown in Figure 2.

A total of 13809 men and women aged 30 years or older, who died from CRCs with an ICD-9 code of 153.0-154.1, were initially selected for the study. Among them, 12942, accounting for $93.7 \%$ of 13809 deaths due to CRCs, were taken as cases, excluding subjects with missing sex or smoking information.

We selected 325255 surviving spouses of all 1134919 all-cause deaths as controls. The age of the spouses was confirmed according to the matching cases' age at death. Among 325255 surviving spouses, 6125 were excluded owing to missing data on age or previous diagnosis of $\mathrm{CRC}$ at the time of the interview. An additional 6950 controls were excluded because of missing data on

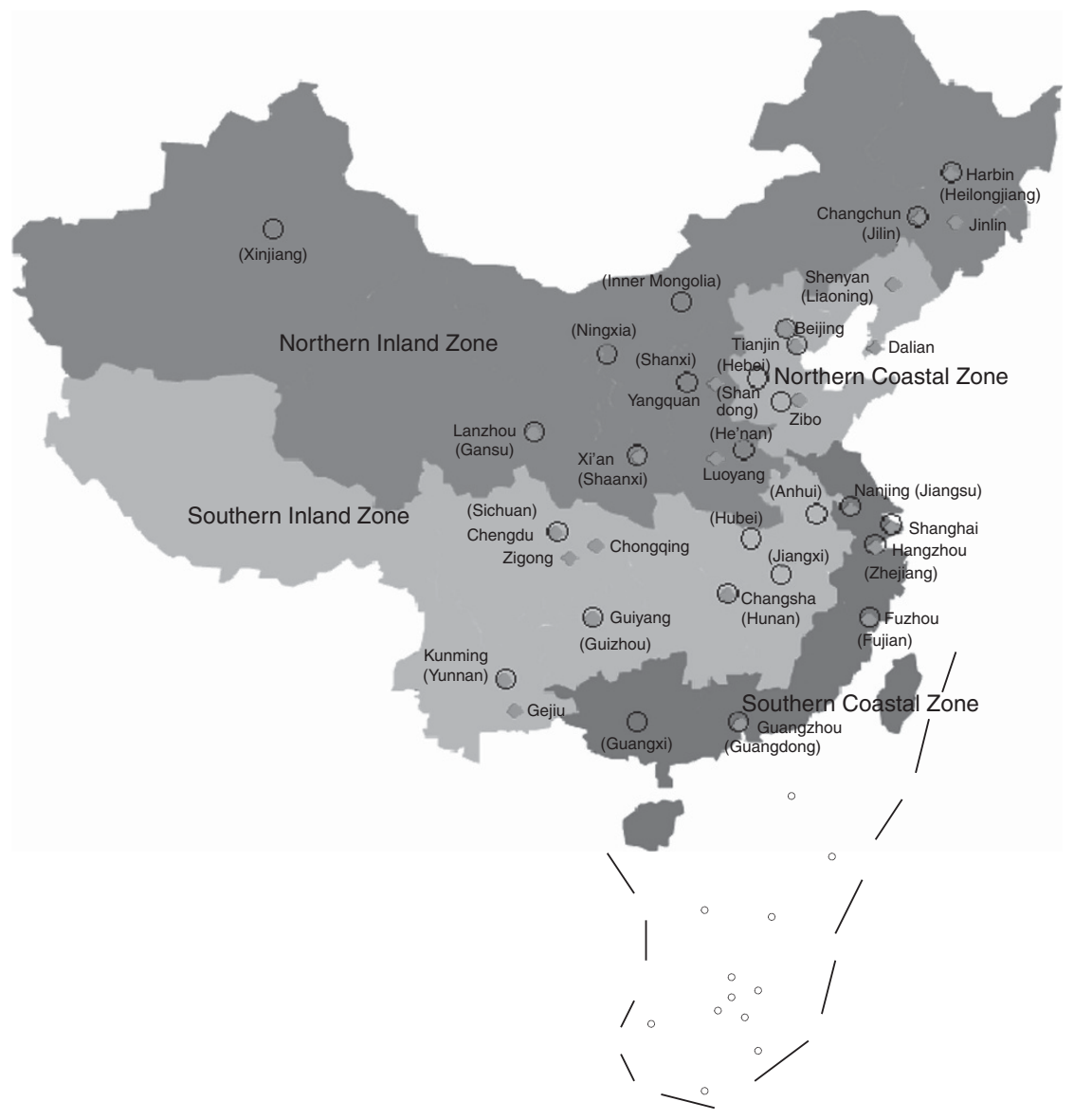

Figure 1. China geographic division. Liaoning, Beijing, Tianjin, Hebei, and Shandong belong to the northern coastal zone; Jiangsu, Shanghai, Zhejiang, Fujian, Guangdong, and Guangxi belong to the southern coastal zone; Heilongjiang, Jilin, Inner Mongolia, Shanxi, Shaanxi, He'nan, Gansu, Ningxia, and Xinjiang belong to the northern inland zone; and Hubei, Hunan, Anhui, Jiangxi, Chongqing, Sichuan, Guizhou, and Yunnan belong to the southern inland zone in this study. $\diamond: 24$ cities sampled. $\bigcirc: 26$ provincial administrative regions where rural counties were randomly sampled. 


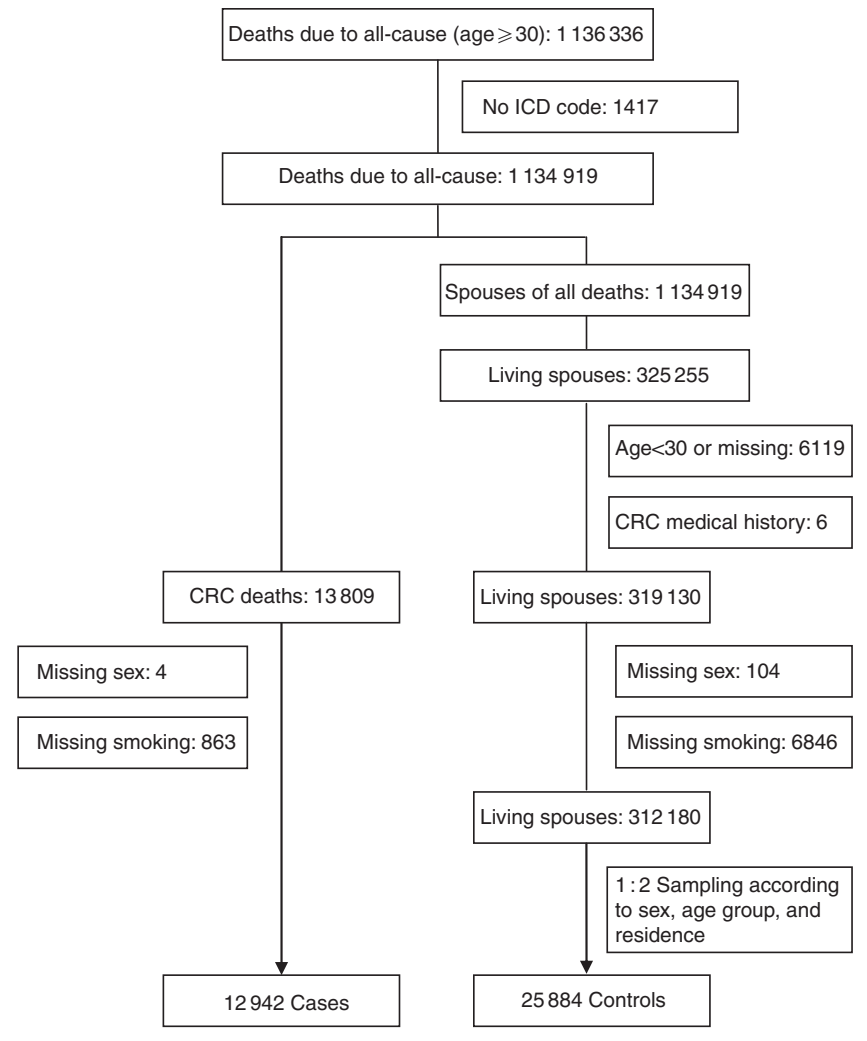

Figure 2. Flowchart for recruitment of the case and control.

sex or smoking history, leaving 312180 subjects, randomly assigned to deaths due to CRCs. Controls were assigned to cases based on a ratio of two controls for each case, according to sex and age span of ten from 30 to over 80 years old, separately in 103 study areas, of which four were combined with neighbouring rural areas because of a small sample size, using a computer-generated allocation algorithm designed for this purpose. Last, 25884 controls representing $97.8 \%$ (312 180/319 130) of all qualified living spouses in the study base were analysed in this study. This control selection procedure was based on the assumption that individuals in the control group, who were able to represent the source population, had smoking habits similar to those of the study base.

Smoking survey data. Spouses or other relatives of all deceased persons in the national mortality survey were interviewed to obtain information on smoking histories. The interviewees described smoking habits of their deceased family members and their own. These data were used to determine whether people had ever smoked by 1980, a period of time before onset of their disease, in order to decrease a survival bias. Smoking was defined as at least one cigarette smoked. The other information concerning smoking history included age at onset of daily smoking and number of cigarettes smoked daily. For smokers, we defined years of smoking as current age (age at death for the case or spouse's age at the time of case's death) minus age at onset of daily smoking. The proportion of former smokers, who had quit smoking for at least 2 years, is very low in China (3.5\%), according to China National Smoking Prevalence Survey conducted in 1984 and during 1995-1996.

Statistical methods. The overall association between smoking and CRC-specific mortality was analysed for all cases and controls and separately by sex, age group, and residence (urban or rural). The odds ratio (OR) was used to estimate the effects of smoking history on the risk of CRC deaths. In a multiple-factor analysis, the non-conditional logistic regression model was used to estimate the risk of smoking when adjusting for confounding factors such as sex, age, and residence. Attributable fractions (AFs), calculated as $(\mathrm{OR}-1) / \mathrm{OR}$, were used to express risk attributing to CRC deaths for the smoking population. Population attributable fractions (PAFs), calculated as $\mathrm{p} \times(\mathrm{OR}-1) /(1+\mathrm{p} \times(\mathrm{OR}-1))$ in which $\mathrm{p}$ was smoking prevalence in the control group, were used to express risk attributing to $\mathrm{CRC}$ deaths for the total population. Both AFs and PAFs were used to estimate the potential impact of tobacco control programs aimed at smoking prevention and cessation. All analyses were performed using the SAS 9.2 statistical software package (SAS, Beijing, China).

\section{RESULTS}

Table 1 shows the numbers of cases and controls in all subgroups, defined by residence, sex, and age group. The age distribution of cases and controls was comparable $(63.80 \pm 13.31$ years $v s$ $63.46 \pm 12.86$ years). The study group included $51.5 \%$ males and $48.5 \%$ females, $78.2 \%$ from urban areas and $21.8 \%$ from rural areas. In general, there was a slightly higher prevalence of smoking of $38.7 \%$ in the case group in comparison with $36.9 \%$ in the control group. This led to a modestly increased risk of CRC deaths due to smoking of $9.8 \%(\mathrm{OR}=1.098,95 \% \mathrm{CI}=1.046-1.153)$ for all adjusted for sex, age, and residence, $10.8 \%(\mathrm{OR}=1.108,95 \%$ $\mathrm{CI}=1.043-1.177) \quad$ for $\mathrm{men}$, and $7.3 \% \quad(\mathrm{OR}=1.073, \quad 95 \%$ $\mathrm{CI}=0.986-1.167)$ for women adjusted for age and residence, compared with non-smokers. Cigarette smoking can account for 8.9\% CRC deaths for smokers and 3.5\% CRC deaths for the entire population.

The stratified analysis according to sex, age group, and residence displayed a dose-response relationship between smoking variables, such as years of smoking, cigarettes smoked daily, and age at onset of smoking, and CRC deaths, as shown in Table 2, although a significant linear trend was not observed in some subgroups, typically in women, probably owing to an exposure proportion far lower than in men. Among urban men compared with rural men, the top dose of years of smoking, cigarettes smoked daily, and the age at onset of smoking significantly increased the risk of CRC deaths by $3.0 \%(\mathrm{OR}=1.030,95 \% \mathrm{CI}=1.006-1.055)$ vs $10.9 \%$ $(\mathrm{OR}=1.109, \quad 95 \% \quad \mathrm{CI}=1.059-1.162), \quad 5.6 \% \quad(\mathrm{OR}=1.056, \quad 95 \%$ $\mathrm{CI}=1.026-1.088)$ vs $14.8 \%(\mathrm{OR}=1.148,95 \% \mathrm{CI}=1.086-1.213)$, and $4.3 \% \quad(\mathrm{OR}=1.043, \quad 95 \% \quad \mathrm{CI}=1.002-1.086) \quad$ vs $\quad 17.7 \%$ $(\mathrm{OR}=1.177,95 \% \mathrm{CI}=1.090-1.270)$, respectively. Obviously, the rural individuals had higher excess risk of CRC deaths than the urban individuals in each stratum of smoking variables. After setting all variables indicating dose level of smoking as ordinal ones according to Table 2 and adjusting for age, sex, and residence, years of smoking and cigarettes smoked daily independently increased the risk of CRC deaths by $4.1 \%$ $(\mathrm{OR}=1.041,95 \% \mathrm{CI}=1.023-1.060)$ and $6.3 \%(\mathrm{OR}=1.063,95 \%$ $\mathrm{CI}=1.040-1.085)$, followed by one step-width increment, respectively. Each step-width decrement of age at onset of smoking independently increased the CRC risk by $7.0 \%(\mathrm{OR}=1.070,95 \%$ $\mathrm{CI}=1.038-1.103)$.

Last, long-term heavy smoking, defined as individuals aged 50 years or older with up to 30 years of smoking and 20 cigarettes smoked daily, led to excess risk of CRC deaths by $30.2 \%$ $(\mathrm{OR}=1.302,95 \% \mathrm{CI}=1.214-1.397)$, although a significance was not observed in the rural women probably owing to underpowering. The effect of smoking on CRC deaths in urban men, urban women, rural men, and rural women, with a significant linear trend $(P$ for trend $<0.05)$ among mild-medium and long-term heavy smokers compared with non-smokers, is shown in Table 3. Typically for rural men, mild-medium and long-term heavy 
Table 1. Comparison of current smoking prevalence and odds ratios among subgroups

\begin{tabular}{|c|c|c|c|c|}
\hline & Control (\%) & Case (\%) & Crude OR $(95 \% \mathrm{Cl})$ & Age-adjusted OR $(95 \% \mathrm{Cl})$ \\
\hline \multicolumn{5}{|c|}{ Urban men } \\
\hline $\begin{array}{l}30 \sim \\
40 \sim \\
50 \sim \\
60 \sim \\
70 \sim \\
\text { Subtotal }\end{array}$ & $\begin{array}{r}632(60.60) \\
718(57.80) \\
2110(59.38) \\
3076(59.23) \\
3738(50.59) \\
10274(56.10)\end{array}$ & $\begin{array}{r}316(57.28) \\
359(57.94) \\
1055(58.96) \\
1538(61.70) \\
1869(53.34) \\
5137(57.56)\end{array}$ & $\begin{array}{l}0.872(0.663-1.147) \\
1.006(0.778-1.300) \\
0.983(0.845-1.142) \\
1.109(0.978-1.257) \\
1.117(0.999-1.248) \\
1.061(0.992-1.136)\end{array}$ & $\begin{array}{l}0.888(0.668-1.181) \\
1.007(0.779-1.301) \\
0.985(0.848-1.146) \\
1.110(0.979-1.258) \\
1.136(1.016-1.270) \\
1.063(0.993-1.137)\end{array}$ \\
\hline \multicolumn{5}{|c|}{ Urban women } \\
\hline $\begin{array}{l}30 \sim \\
40 \sim \\
50 \sim \\
60 \sim \\
70 \sim \\
\text { Subtotal }\end{array}$ & $\begin{array}{c}712(2.53) \\
796(7.04) \\
1970(16.40) \\
2606(20.11) \\
3894(18.88) \\
9978(16.60)\end{array}$ & $\begin{array}{r}356(1.97) \\
398(8.29) \\
985(15.43) \\
1303(20.57) \\
1947(21.62) \\
4989(17.66)\end{array}$ & $\begin{array}{l}0.773(0.320-1.869) \\
1.195(0.763-1.870) \\
0.930(0.754-1.148) \\
1.029(0.872-1.213) \\
1.186(1.037-1.356) \\
1.078(0.985-1.179)\end{array}$ & $\begin{array}{l}0.809(0.334-1.960) \\
1.201(0.766-1.883) \\
0.935(0.758-1.154) \\
1.019(0.863-1.202) \\
1.222(1.067-1.400) \\
1.065(0.973-1.166)\end{array}$ \\
\hline \multicolumn{5}{|c|}{ Rural men } \\
\hline $\begin{array}{l}30 \sim \\
40 \sim \\
50 \sim \\
60 \sim \\
70 \sim \\
\text { Subtotal }\end{array}$ & $\begin{array}{r}186(72.04) \\
282(68.09) \\
586(68.09) \\
916(65.83) \\
1078(54.55) \\
3048(62.86)\end{array}$ & $\begin{array}{r}93(58.06) \\
141(65.25) \\
293(70.99) \\
458(77.73) \\
539(61.97) \\
1524(68.50)\end{array}$ & $\begin{array}{l}0.537(0.319-0.905) \\
0.880(0.574-1.350) \\
1.147(0.844-1.558) \\
1.812(1.398-2.347) \\
1.357(1.099-1.677) \\
1.285(1.128-1.464)\end{array}$ & $\begin{array}{l}0.523(0.309-0.886) \\
0.863(0.561-1.326) \\
1.147(0.845-1.559) \\
1.807(1.394-2.342) \\
1.383(1.118-1.711) \\
1.294(1.134-1.475)\end{array}$ \\
\hline \multicolumn{5}{|c|}{ Rural women } \\
\hline $\begin{array}{l}30 \sim \\
40 \sim \\
50 \sim \\
60 \sim \\
70 \sim \\
\text { Subtotal }\end{array}$ & $\begin{array}{c}146(0.68) \\
210(3.81) \\
440(7.50) \\
708(8.90) \\
1080(10.65) \\
2584(8.51)\end{array}$ & $\begin{array}{c}73(4.11) \\
105(4.76) \\
220(8.18) \\
354(9.89) \\
540(11.67) \\
1292(9.60)\end{array}$ & $\begin{array}{l}6.214(0.635-60.821) \\
1.263(0.403-3.959) \\
1.099(0.604-2.000) \\
1.123(0.728-1.735) \\
1.108(0.800-1.536) \\
1.141(0.906-1.437)\end{array}$ & $\begin{array}{l}5.186(0.523-51.445) \\
1.218(0.387-3.832) \\
1.097(0.603-1.997) \\
1.085(0.701-1.680) \\
1.166(0.839-1.619) \\
1.128(0.895-1.422)\end{array}$ \\
\hline
\end{tabular}

smoking separately increased the risk of CRC deaths by $19.3 \%$ $(\mathrm{OR}=1.193,95 \% \mathrm{CI}=1.037-1.372)$ and $60.4 \%(\mathrm{OR}=1.604,95 \%$ $\mathrm{CI}=1.341-1.919)$, although a statistical significance between long-term heavy smokers and non-smokers was not observed in foreland zone in north China after stratifying according to zones. It was noted that there was such a high prevalence of long-term heavy smoking, probably resulting in a significant association between smoking and CRC deaths, among men in south China. Even if women had a much lower smoking prevalence than men, urban women in the foreland zone of the north had significantly increased excess risk of CRC deaths by up to $80.0 \%(\mathrm{OR}=1.800$, $95 \% \mathrm{CI}=1.262-2.568$ ).

\section{DISCUSSION}

This is the first national-level study in China indicating an association between cigarette smoking and CRC deaths. Our main finding showed that cigarette smoking increased the risk of CRC-specific mortality, especially for long-term, heavy smokers. The CRC risk increased with increasing years of smoking and number of cigarettes smoked daily.

Our results showed a statistically significant excess CRC-specific mortality risk from cigarette smoking of $9.8 \%$. Studies in American veterans showed a $22 \%$ increased risk for rectal cancer mortality and $16 \%$ for colon cancer mortality (Heineman et al, 1994). The
Cancer Prevention Study II (CPS II) reported a 32\% increased CRC risk (Chao et al, 2000), and the Nurses' Health Study produced a $63 \%$ increased risk for CRC-specific mortality (Kenfield et al, 2008). Our results are partly supported by incidence studies conducted among the Chinese population living in Hong Kong (Ho et al, 2004) and Singapore (Tsong et al, 2007). However, the association between smoking and CRC was not observed in two studies in Shanghai Chinese, although CRC incidence and mortality outcomes were separately used in these two studies (Chen et al, 1997; Ji et al, 2002). Of particular interest is the prospective observational study of mortality in relation to tobacco use, reported by Chen et al (1997). The study found a relative risk of 1.8 , which was, however, not statistically significant $(P=0.13)$. This study of CRC and cigarette smoking was seemingly underpowered because it was based on 9351 factory workers, producing a small number of 22 CRC deaths among the Shanghai Chinese, which included and constituted a small proportion of all-cause deaths (2.5\%).

Carcinogens in cigarette smoke are hypothesised to act as tumour initiators for CRC with an induction period of 35-40 years (Giovannucci and Martínez, 1996). This hypothesis was partly supported by two cohort studies such as the Nurses' Health Study (Kenfield et al, 2008) and the American Veterans' Study (Heineman et al, 1994) with over a 20 -year follow-up. In the past four decades, two meta-analyses have summarised the results from several studies, which support the hypothesis that smoking is a risk factor of CRC, showing that smoking slightly increases the risk of 


\begin{tabular}{|c|c|c|c|c|c|c|c|c|}
\hline & \multicolumn{4}{|c|}{ Men } & \multicolumn{4}{|c|}{ Women } \\
\hline & $\begin{array}{c}\text { Control } \\
(\%)\end{array}$ & $\begin{array}{l}\text { Case } \\
(\%)\end{array}$ & $\begin{array}{c}\text { Crude OR } \\
(95 \% \mathrm{Cl})\end{array}$ & $\begin{array}{l}\text { Age-adjusted } \\
\text { OR }(95 \% \mathrm{Cl})\end{array}$ & $\begin{array}{c}\text { Control } \\
(\%)\end{array}$ & $\begin{array}{l}\text { Case } \\
(\%)\end{array}$ & $\begin{array}{l}\text { Crude OR } \\
(95 \% \mathrm{Cl})\end{array}$ & $\begin{array}{l}\text { Age-adjusted } \\
\text { OR }(95 \% \mathrm{Cl})\end{array}$ \\
\hline \multicolumn{9}{|l|}{ Urban } \\
\hline Non-smoker & $4510(43.90)$ & $2180(42.44)$ & 1.000 & 1.000 & $8322(83.40)$ & $4108(82.34)$ & 1.000 & 1.000 \\
\hline \multicolumn{9}{|c|}{ Years of smoking } \\
\hline$<20$ & $602(5.86)$ & $267(5.20)$ & $0.917(0.788-1.069)$ & $0.851(0.715-1.014)$ & $171(1.71)$ & $79(1.58)$ & $0.936(0.715-1.225)$ & $0.944(0.721-1.236)$ \\
\hline $20 \sim 29$ & $750(7.30)$ & $355(6.91)$ & $0.979(0.855-1.122)$ & $0.973(0.905-1.045)$ & $221(2.21)$ & $102(2.04)$ & $0.935(0.737-1.186)$ & $0.970(0.861-1.093)$ \\
\hline $\begin{array}{l}\geqslant 30 \\
P \text { for trend }\end{array}$ & $4412(42.44)$ & $2335(45.45)$ & $\begin{array}{c}1.095(1.019-1.176) \\
<0.001\end{array}$ & $1.030(1.006-1.055)$ & $1264(12.67)$ & $700(14.03)$ & $\begin{array}{c}1.122(1.016-1.239) \\
0.045\end{array}$ & $1.033(0.998-1.068)$ \\
\hline \multicolumn{9}{|c|}{ Cigarettes smoked daily } \\
\hline$<10$ & 1605 (15.62) & 804 (15.65) & $1.036(0.939-1.144)$ & $1.037(0.939-1.145)$ & $802(8.04)$ & $392(7.86)$ & $0.990(0.873-1.124)$ & $0.982(0.865-1.115)$ \\
\hline $10 \sim 19$ & 2027 (19.73) & $941(18.32)$ & $0.960(0.875-1.054)$ & $0.979(0.935-1.026)$ & $555(5.56)$ & $290(5.81)$ & $1.069(0.914-1.226)$ & $1.023(0.951-1.102)$ \\
\hline$\geqslant 20$ & $2132(20.75)$ & $1212(23.59)$ & $1.176(1.078-1.283)$ & $1.056(1.026-1.088)$ & $299(3.00)$ & 199 (3.99) & $1.348(1.123-1.619)$ & $1.102(1.037-1.171)$ \\
\hline$P$ for trend & & & $<0.001$ & & & & 0.008 & \\
\hline \multicolumn{9}{|c|}{ Age at onset of smoking } \\
\hline$>20$ & $2883(28.06)$ & $1440(28.03)$ & $1.033(0.953-1.121)$ & $1.034(0.953-1.122)$ & $1017(10.19)$ & $524(10.50)$ & $1.044(0.933-1.167)$ & $1.034(0.924-1.157)$ \\
\hline$\leqslant 20$ & $2881(28.04)$ & $1517(29.53)$ & 1.089 (1.005-1.181) & $1.043(1.002-1.086)$ & $639(6.40)$ & $357(7.16)$ & 1.132 (0.989-1.295) & $1.058(0.989-1.133)$ \\
\hline$P$ for trend & & & $<0.001$ & & & & 0.062 & \\
\hline \multicolumn{9}{|l|}{ Rural } \\
\hline Non-smoker & $1132(37.14)$ & $480(31.50)$ & 1.000 & 1.000 & $2364(91.49)$ & $1168(90.40)$ & 1.000 & 1.000 \\
\hline \multicolumn{9}{|c|}{ Years of smoking } \\
\hline$<20$ & $200(6.56)$ & $83(5.45)$ & $0.979(0.742-1.291)$ & $0.829(0.597-1.150)$ & $28(1.08)$ & $15(1.16)$ & $1.084(0.577-2.038)$ & $1.106(0.588-2.081)$ \\
\hline $20 \sim 29$ & $293(9.61)$ & $142(9.32)$ & $1.143(0.911-1.434)$ & $1.024(0.903-1.160)$ & $24(0.93)$ & $14(1.08)$ & $1.181(0.609-2.291)$ & $1.089(0.782-1.517)$ \\
\hline$\geqslant 30$ & $1423(46.69)$ & 819 (53.74) & $1.357(1.184-1.557)$ & 1.109 (1.059-1.162) & $168(6.50)$ & $95(7.35)$ & $1.145(0.881-1.486)$ & $1.040(0.952-1.135)$ \\
\hline$P$ for trend & & & $<0.001$ & & & & 0.268 & \\
\hline \multicolumn{9}{|c|}{ Cigarettes smoked daily } \\
\hline$<10$ & $628(20.60)$ & $315(20.67)$ & $1.183(0.996-1.405)$ & $1.183(0.995-1.405)$ & $134(5.19)$ & $67(5.19)$ & $1.012(0.749-1.368)$ & $1.000(0.739-1.358)$ \\
\hline $10 \sim 19$ & $657(21.56)$ & $321(21.06)$ & $1.152(0.971-1.367)$ & $1.071(0.983-1.167)$ & $63(2.44)$ & $42(3.25)$ & $1.162(0.953-1.416)$ & $1.155(0.947-1.409)$ \\
\hline$\geqslant 20$ & $631(20.70)$ & $408(26.77)$ & $1.525(1.294-1.797)$ & $1.148(1.086-1.213)$ & $23(0.89)$ & $15(1.16)$ & $1.097(0.882-1.364)$ & $1.095(0.880-1.362)$ \\
\hline$P$ for trend & & & $<0.001$ & & & & 0.136 & \\
\hline \multicolumn{9}{|c|}{ Age at onset of smoking } \\
\hline$>20$ & $1026(33.66)$ & 517 (33.92) & $1.188(1.023-1.381)$ & $1.195(1.028-1.389)$ & $163(6.31)$ & $87(6.73)$ & $1.080(0.825-1.414)$ & $1.064(0.812-1.394)$ \\
\hline$\leqslant 20$ & $890(29.20)$ & $527(34.58)$ & $1.397(1.200-1.625)$ & $1.177(1.090-1.270)$ & $57(2.21)$ & $37(2.86)$ & $1.314(0.864-1.999)$ & $1.145(0.928-1.412)$ \\
\hline$P$ for trend & & & $<0.001$ & & & & 0.185 & \\
\hline
\end{tabular}

CRC mortality by $25 \%-40 \%$ when comparing smokers with nonsmokers (Botteri et al, 2008; Liang et al, 2009). Benzo[a]pyrene and other polycyclic aromatic hydrocarbons (PAHs) from tobacco smoke could have a role in the aetiology of human CRCs (Alexandrov et al, 1996; Phillips, 2002). Recently, new biomedical evidence on nicotine, a major active component of cigarette smoke, suggests that this chemical might serve to promote colorectal cell proliferation (Wong et al, 2007; Cucina et al, 2012), inhibit apoptosis in colon cancer (Cucina et al, 2012), and enhance colon cancer cell migration (Wei et al, 2011).

Various smoking exposure measures including current smoking, age at initiating smoking, smoking duration, and amount of daily cigarette smoking were all shown to be positively associated with increased CRC risk. The CPS II study similarly found a linear trend between CRC deaths and cigarettes smoked daily, pack-years of smoking, and age at onset of smoking after adjusting for current age and other characteristics of subjects (Chao et al, 2000). Our study results suggest that ages 50 years or older might serve as an age threshold for current CRC screening in China using standard guidelines (Qaseem et al, 2012).
The current study findings and reports from the literature are particularly important given the rapidly aging population of China and the movement of large numbers of Chinese from rural to urban areas of the country. It is also important to note that men and women in China start at a young age, with $60.7 \%$ male smokers and $43.1 \%$ female smokers who began smoking at the age of $15-24$ years in this study, compared with $71.8 \%$ and $43.5 \%$ in 1984, respectively. Symptoms of nicotine dependence may develop soon after initiation even at low levels of smoking (Zhan et al, 2012); thus, slower nicotine clearance at adolescence may be associated with greater addiction levels, perhaps mediated by a greater number of cigarettes smoked (Rubinstein et al, 2013). It has been charged that tobacco companies manipulated the sensory characteristics of cigarettes, including menthol content, thereby facilitating smoking initiation and nicotine dependence among adolescents and young adults (Kreslake et al, 2008). Second, Chinese smokers reported smoking on an average of 15 cigarettes daily in 1996 compared with 14.2 cigarettes in GATS China 2010 and 11.9 cigarettes in this study. Third, GATS 2010 showed that only $5.1 \%$ of current Chinese smokers reported that they had a 


\begin{tabular}{|c|c|c|c|c|c|c|c|c|c|}
\hline & \multicolumn{2}{|c|}{ Non-smokers } & \multicolumn{3}{|c|}{ Mild-medium smokers } & \multicolumn{3}{|c|}{ Long-term heavy smokers } & \multirow[b]{2}{*}{$\begin{array}{l}P \text { for } \\
\text { trend }\end{array}$} \\
\hline & $\begin{array}{c}\text { Control } \\
(\%)\end{array}$ & $\begin{array}{c}\text { Case } \\
(\%)\end{array}$ & $\begin{array}{c}\text { Control } \\
(\%)\end{array}$ & $\begin{array}{c}\text { Case } \\
(\%)\end{array}$ & $\begin{array}{c}\text { OR } \\
(95 \% \mathrm{Cl})^{\mathrm{a}}\end{array}$ & $\begin{array}{c}\text { Control } \\
(\%)\end{array}$ & $\begin{array}{c}\text { Case } \\
(\%)\end{array}$ & $\begin{array}{c}\text { OR } \\
(95 \% \mathrm{Cl})^{\mathrm{a}}\end{array}$ & \\
\hline Urban men & $4510(43.90)$ & $2180(42.44)$ & $4112(40.02)$ & $1960(38.15)$ & $0.984(0.913-1.060)$ & $1652(16.08)$ & $997(19.41)$ & $1.250(1.138-1.373)$ & $<0.001$ \\
\hline Foreland region in north China & $1360(48.89)$ & $657(47.23)$ & $1101(39.58)$ & $546(39.25)$ & $1.024(0.890-1.178)$ & $321(11.54)$ & $188(13.52)$ & $1.212(0.990-1.485)$ & 0.109 \\
\hline Foreland region in south China & $1760(43.35)$ & $902(44.43)$ & $1512(37.24)$ & $644(31.72)$ & $0.829(0.733-0.937)$ & $788(19.41)$ & $484(23.84)$ & $1.202(1.046-1.382)$ & 0.110 \\
\hline Inland region in north China & $571(50.44)$ & $270(47.70)$ & $449(39.66)$ & $231(40.81)$ & $1.085(0.874-1.347)$ & $112(9.89)$ & $65(11.48)$ & $1.235(0.880-1.732)$ & 0.208 \\
\hline Inland region in south China & 819 (35.61) & $351(30.52)$ & $1050(45.65)$ & $539(46.87)$ & $1.198(1.018-1.411)$ & $431(18.74)$ & $260(22.61)$ & $1.401(1.149-1.710)$ & 0.001 \\
\hline Urban women & $8322(83.40)$ & $4108(82.34)$ & $1427(14.30)$ & 708 (14.19) & $0.996(0.903-1.098)$ & $229(2.30)$ & $173(3.47)$ & $1.512(1.236-1.850)$ & $<0.001$ \\
\hline Foreland region in north China & $1951(75.97)$ & $946(73.68)$ & $548(21.65)$ & $278(21.34)$ & $1.043(0.885-1.229)$ & $69(2.69)$ & $60(4.67)$ & $1.800(1.262-2.568)$ & 0.016 \\
\hline Forland region in south China & $3501(84.57)$ & $1754(84.73)$ & $537(12.97)$ & $246(11.88)$ & $0.897(0.762-1.055)$ & $102(2.46)$ & $70(3.38)$ & $1.344(0.985-1.833)$ & 0.538 \\
\hline Inland region in north China & $969(85.75)$ & $476(84.25)$ & $141(12.48)$ & $71(12.57)$ & $1.015(0.747-1.379)$ & $20(1.77)$ & $18(3.19)$ & $1.796(0.939-3.437)$ & 0.188 \\
\hline Inland region in south China & $1901(88.83)$ & $932(87.10)$ & $201(9.39)$ & $113(10.56)$ & $1.138(0.891-1.454)$ & $38(1.78)$ & $25(2.34)$ & $1.321(0.792-2.205)$ & 0.123 \\
\hline Rural men & $1132(37.14)$ & $480(31.50)$ & $1454(47.70)$ & $732(48.03)$ & $1.193(1.037-1.372)$ & 462 (15.16) & $312(20.47)$ & $1.604(1.341-1.919)$ & $<0.001$ \\
\hline Foreland region in north China & $142(52.59)$ & $68(50.37)$ & $106(39.26)$ & $54(40.00)$ & $1.062(0.682-1.652)$ & $22(8.15)$ & $13(9.63)$ & $1.222(0.579-2.577)$ & 0.587 \\
\hline Foreland region in south China & $522(33.12)$ & $214(27.16)$ & $731(46.38)$ & $364(46.19)$ & $1.205(0.993-1.498)$ & 323 (20.49) & $210(26.65)$ & $1.598(1.262-2.024)$ & $<0.001$ \\
\hline Inland region in north China & $254(42.19)$ & $111(36.88)$ & $305(50.66)$ & $156(51.83)$ & $1.183(0.878-1.592)$ & $43(7.14)$ & $34(11.30)$ & $1.854(1.120-3.069)$ & 0.031 \\
\hline Inland region in south China & $214(35.67)$ & $87(29.00)$ & $312(52.00)$ & $158(52.67)$ & $1.245(0.909-1.705)$ & $74(12.33)$ & $55(18.33)$ & $1.796(1.166-2.768)$ & 0.007 \\
\hline Rural women & $2364(91.49)$ & $1168(90.40)$ & $205(7.93)$ & $110(8.51)$ & $1.074(0.843-1.369)$ & $15(0.58)$ & $14(1.08)$ & $1.864(0.896-3.876)$ & 0.016 \\
\hline Foreland region in north China & $227(91.53)$ & $112(90.32)$ & $20(8.06)$ & $11(8.87)$ & $1.115(0.516-2.407)$ & $1(0.40)$ & $1(0.81)$ & $1.926(0.119-31.184)$ & - \\
\hline Foreland region in south China & $1375(91.91)$ & $680(90.91)$ & $109(7.29)$ & $58(7.75)$ & $1.076(0.772-1.499)$ & $12(0.8)$ & $10(1.34)$ & $1.665(0.715-3.876)$ & 0.289 \\
\hline Inland region in north China & $380(90.91)$ & $185(88.52)$ & $38(9.09)$ & $22(10.53)$ & $1.189(0.684-2.069)$ & 0 & $2(0.96)$ & - & - \\
\hline Inland region in south China & $382(90.52)$ & $191(90.52)$ & $38(9.00)$ & $19(9.00)$ & $1.000(0.561-1.782)$ & $2(0.47)$ & $1(0.47)$ & $1.014(0.091-11.265)$ & - \\
\hline Total & $16328(63.08)$ & $79.36(61.32)$ & $7198(27.81)$ & $3510(27.12)$ & $1.003(0.956-1.053)$ & $2358(9.11)$ & $1496(11.56)$ & \begin{tabular}{|l|}
$1.302(1.214-1.397)$ \\
\end{tabular} & $<0.001$ \\
\hline
\end{tabular}

plan to quit, which was the second lowest quit-rate among all GATS countries. The results from our study, and the results from other studies reported in the literature, and the fact that China has maintained the three negative characteristics mentioned above underscore the importance of enhancing current efforts aimed at smoking prevention and cessation. In addition, China is the world's most populous country with the largest aging population. China has 338 million people aged 50 years and older (data from National Bureau of Statistics of China), which represents the bulk of long-term heavy smokers.

Second, our results showed that tobacco use was consistently associated with CRC death in both urban and rural areas. This finding suggests that rapid urbanisation in China would not change the relationship between smoking and CRC. More importantly, because tobacco use was the highest in rural men (62.9\%) who showed the strongest relationship between smoking and CRC probably because of a higher dose of smoking, for example, 15.0 vs 13.8 cigarettes daily according to the 3rd National Smoking Survey in 2002 as supported by Table 2, other factors such as dietary patterns might combine with smoking to influence CRC risk. The combination of these factors might explain recent increases in CRC incidence in urban than in rural areas and an increase of incidence and mortality of CRC in China as a whole. Currently, China has a highly mobile population of 252 million migrant workers, moving from country to city in search of work (data from National Bureau of Statistics of China). Migrants, likely with less health awareness, were much less involved in China's urban services, including access to public health (Hu et al, 2008). In addition, national policy established on locality-based household registration made it difficult to transfer social benefits from rural to urban areas. Non-infectious chronic diseases including CRC in migrant workers were still not a focus of the healthcare community in China. Therefore, materials and data on health of Chinese migrant workers are lacking. In China, $65.9 \%$ migrant workers were men and $14.3 \%$ migrant workers were aged 50 years or older, a segment of the rural population who would be most likely to return to their rural areas owing to their difficulty to adapt to an urban lifestyle. Considering their high smoking prevalence, and the strong association between smoking and CRC in these men, as well as less accessibility of health services, we were concerned that the 100 million male migrant workers will suffer higher rates of CRC incidence and death.

Moreover, geographic variations in the current study were observed, but not reported, in other literature (Table 3). For example, although the men in south China had a lower smoking prevalence, they had a much higher prevalence of long-term heavy smoking, that is, $12.3 \%-20.5 \%$ vs $7.1 \%-11.5 \%$, which seemingly led to a significant causal linkage, when compared with men in north China. In particular, rural men showed a much stronger association between smoking and CRC in the inland zone, where a large percentage of rural workers migrate from, when compared with men in the foreland zone of China. For women with a low smoking prevalence, we found only a significantly positive association in the urban people of the northern foreland zone, and the association in women seemed stronger in this zone than that observed in men. This likely implied that women were more vulnerable than men to the dangers of tobacco or that they may have larger exposures to passive or involuntary smoking in the home or workplace. Our findings were seemingly supported by some smallsample-size case-control studies including reports in Chinese literature, for example, an association was not seen in rural people of Beijing (Foreland zone in north China; Li et al, 2003), but was seen in Guangzhou (Chen et al, 2001) and Hong Kong (Ho et al, 2004) people (Forland zone in south China); a positive association was observed in Jiashan county (Jiang et al, 2004), whereas on the contrary it was not seen in urban Shanghai (Ji et al, 2002) and Cixi city near Jiashan (Foreland zone in south China; Ye and Shi, 2007), although two studies in Wuhan (Inland zone in south China) displayed a controversial result (Yao et al, 2001; Nie et al, 2002). 


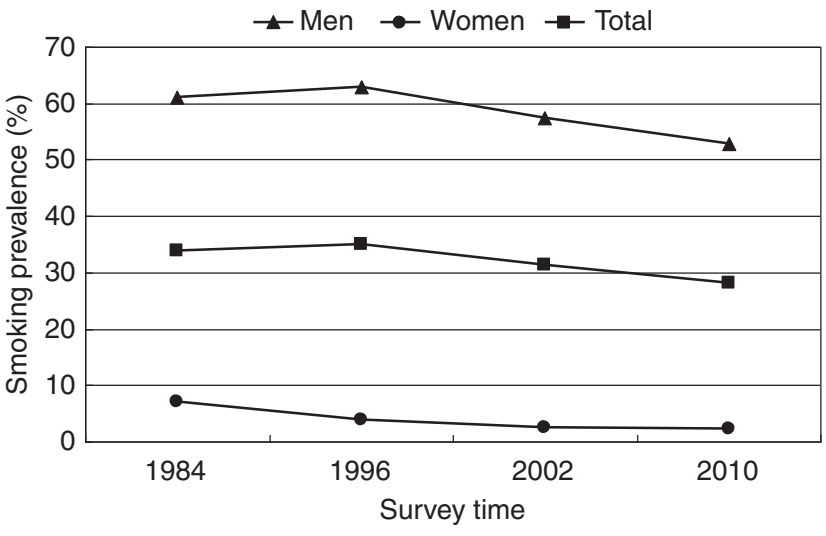

Figure 3. Smoking prevalence from four China national smoking surveys for adults aged 15 years or older.

On the basis of the results from the current study, rural men or long-term, heavy smokers are estimated to have the largest preventive effect from tobacco prevention and cessation. The current data suggest that reduction in CRC in this segment of the population would be up to $32.1 \%$ and $22.7 \%$, respectively. In particular, $15.6 \%$ of all CRC deaths in rural men would be prevented if tobacco use ceased in this group.

A key strength of this study is that it is a high-quality, nationallevel, population-based case-control study. A random sample of living spouses was selected using a standardized algorithm. This approach was designed to ensure that the sample of control spouses would have similar smoking habits as those in the study base; hence, differences between the recorded proportion of smokers in the case and control group can be used to calculate unbiased odds ratios.

The four national smoking surveys in China in the past three decades implied a steady smoking pattern with a mildly decreasing trend of current smoking prevalence from $33.88 \%$ in 1984 to $28.1 \%$ in 2010 for adults aged 15 years or older as shown in Figure 3; therefore, we can use the aetiological linkage, for example, ORs, from national survey data collected during 1989-1991 to get some implications for tobacco control of current China. Although smoking modestly increased CRC risk summarily in this study, the absolute numbers of people at risk and the relatively high risk for specified populations, such as long-term heavy smokers, cannot be ignored. This study, however, could not exclude recall bias and the measurement error from surviving spouses, which might attenuate the association between smoking and CRC. In addition, rural people usually had less education and understanding for questionnaire than urban ones. Moreover, more disease exposures except smoking and better healthcare conditions happened in urban areas compared with rural areas. These might result in underestimating the risk from CRC-specific mortality. Last, although a small proportion of diagnosed CRC cases have known risk factors, such as family history of CRC (Singh et al, 2009), our results were still likely limited by not adjusting for confounders other than sex, age, and area.

In summary, this study adds new evidence to support an association between tobacco use and CRC in China. Given the relationships between smoking and various forms of cancer and cardiovascular disease, it is highly advisable that the government develop strong tobacco prevention and cessation programs in both rural and urban areas of China. For long-term heavy smokers, cigarette smoking should be considered to be a factor of risk stratification of individuals attending CRC screening. Furthermore, sponsors of tobacco control campaign and providers of public healthcare on CRC should be advised to pay increased attention to migrant workers, especially male smokers from inland rural areas who are at a high risk of CRC. Considering regional differences in smoking prevalence and the strength of the association between smoking and CRC, smoking prevention and cessation programs could be focused on both the rural and urban men in the south of China, as well as the rural men in the inland area and the urban women in the foreland of north China.

\section{ACKNOWLEDGEMENTS}

Medical Research Council and Imperial Cancer Research Fund in Britain, US National Institutes of Health, the Chinese Ministry of Health, and the Chinese Academy of Medical Sciences funded the original survey. Professor Richard Peto, the local government, and thousands of doctors, nurses, and other field workers gave great support to this project. This work, including analysis, decision to publish, and preparation of the manuscript, has been supported by a UICC International Cancer Technology Transfer Fellowship and with Federal funds from the National Cancer Institute, National Institutes of Health under Contract NO2-CO-41101.

\section{CONFLICT OF INTEREST}

The authors declare no conflict of interest.

\section{REFERENCES}

Alexandrov K, Rojas M, Kadlubar FF, Lang NP, Bartsch H (1996) Evidence of anti-benzo[a]pyrene diolepoxide-DNA adduct formation in human colon mucosa. Carcinogenesis 17: 2081-2083.

Botteri E, Iodice S, Bagnardi V, Raimondi S, Lowenfels AB (2008) Smoking and colorectal cancer: a meta-analysis. JAMA 300: 2765-2778.

Cavalli F (2013) An appeal to world leaders: stop cancer now. Lancet 381: $425-426$.

Chao A, Thun MJ, Jacobs EJ, Henley SJ, Rodriguez C (2000) Cigarette smoking and colorectal cancer mortality in the cancer prevention study II. J Natl Cancer Inst 92: 1888-1896.

Chen ZM, Xu Z, Collins R, Li WX, Peto R (1997) Early health effects of the emerging tobacco epidemic in China. A 16-year prospective study. JAMA 278: 1500-1504.

Chen G, Wan DS, Pan ZZ, Zhou ZW, Chen YB, Ding HF, Wang LY, Liu YL, Deng F (2001) [A case-control study on risk factors of colon cancer in Guangzhou]. Chin J Cancer 20: 1086-1088 (in Chinese).

Cucina A, Dinicola S, Coluccia P, Proietti S, D’Anselmi F (2012) Nicotine stimulates proliferation and inhibits apoptosis in colon cancer cell lines through activation of survival pathways. J Surg Res 178: $233-241$.

GATS China Workgroup (2011) Global Adult Tobacco Survey (GATS) China 2010 Country Report. Chinese Center for Disease Control and Prevention. China Three Gorges Publishing House: Beijing, China.

Giovannucci E, Martínez ME (1996) Tobacco, colorectal cancer, and adenomas: a review of the evidence. J Natl Cancer Inst 88: 1717-1730.

Heineman EF, Zahm SH, McLaughlin JK, Vaught JB (1994) Increased risk of colorectal cancer among smokers: results of a 26-year follow-up of US veterans and a review. Int J Cancer 59: 728-738.

Hu X, Cook S, Salazar MA (2008) Internal migration and health in China. Lancet 372: 1717-1719.

Ho JW, Lam TH, Tse CW, Chiu LK, Lam HS (2004) Smoking, drinking and colorectal cancer in Hong Kong Chinese: a case-control study. Int J Cancer 109: 587-597.

Ji BT, Dai Q, Gao YT, Hsing AW, McLaughlin JK (2002) Cigarette and alcohol consumption and the risk of colorectal cancer in Shanghai, China. Eur J Cancer Prev 11: 237-244.

Jiang QT, Chen Q, Zou Y, Zhao YW, Ma XY, Li QL, Yao KY, Zheng S (2004) [The case-control study on relationship between environmental risk exposure and incidence of colorectal cancer in the population-based cohort]. Tumor 24: 6-10 (in Chinese). 
Kenfield SA, Stampfer MJ, Rosner BA, Colditz GA (2008) Smoking and smoking cessation in relation to mortality in women. JAMA 299: 2037-2047.

Kreslake JM, Wayne GF, Alpert HR, Koh HK, Connolly GN (2008) Tobacco industry control of menthol in cigarettes and targeting of adolescents and young adults. Am J Public Health 98: 1685-1692.

Li Q, Hsia J, Yang G (2011) Prevalence of smoking in China in 2010. N Engl J Med 364: 2469-2470.

Li L, Wang QJ, Zhu WX, Xing XM, Guo J (2003) [A case-control study for colon cancer in Beijing, China]. Chin J Clin Oncol 30: 556-558 (in Chinese).

Liang PS, Chen TY, Giovannucci E (2009) Cigarette smoking and colorectal cancer incidence and mortality: systematic review and meta-analysis. Int J Cancer 124: 2406-2415.

Liu BQ, Peto R, Chen ZM, Boreham J, Wu YP (1998) Emerging tobacco hazards in China: 1 . Retrospective proportional mortality study of one million deaths. BMJ 317: 1411-1422.

Nie SF, Yao X, Zhu GB, Zhang JR, Xu YH, Wang X (2002) [1:2 matched casecontrol study on risk factors of colorectal cancer in Wuhan]. China Public Health 18: 1482-1484 (in Chinese).

Phillips DH (2002) Smoking-related DNA and protein adducts in human tissues. Carcinogenesis 23: 1979-2004.

Qaseem A, Denberg TD, Hopkins Jr RH, Humphrey LL, Levine J. Clinical Guidelines Committee of the American College of Physicians (2012) Screening for colorectal cancer: a guidance statement from the American College of Physicians. Ann Intern Med 156: 378-386.

Rozen P, Winawer SJ, Waye JD (2002) Prospects for the worldwide control of colorectal cancer through screening. Gastrointest Endosc 55: 755-759.

Rubinstein ML, Shiffman S, Moscicki AB, Rait MA, Sen S (2013) Nicotine metabolism and addiction among adolescent smokers. Addiction 108: 406-412.
Singh H, Daci K, Petersen LA, Collins C, Petersen NJ, Shethia A, El-Serag HB (2009) Missed opportunities to initiate endoscopic evaluation for colorectal cancer diagnosis. Am J Gastroenterol 104: 2543-2554.

Tsong WH, Koh WP, Yuan JM, Wang R, Sun CL (2007) Cigarettes and alcohol in relation to colorectal cancer: the Singapore Chinese Health Study. Br J Cancer 96: 821-827.

Wei PL, Kuo LJ, Huang MT, Ting WC, Ho YS (2011) Nicotine enhances colon cancer cell migration by induction of fibronectin. Ann Surg Oncol 18: 1782-1790.

Wong HP, Yu L, Lam EK, Tai EK, Wu WK (2007) Nicotine promotes cell proliferation via alpha7-nicotinic acetylcholine receptor and catecholamine-synthesizing enzymes-mediated pathway in human colon adenocarcinoma HT-29 cells. Toxicol Appl Pharmacol 221: 261-267.

Yang G (2013) Marketing 'less harmful, low-tar' cigarettes is a key strategy of the industry to counter tobacco control in China. Tob Control; e-pub ahead of print 24 January 2013; doi:10.1136/tobaccocontrol-2012050691.

Yao X, Nie SF, Wei SB, Zhu GB, Wang RR, Zheng X (2001) [A case-control study on risk factors of large bowel cancer in Wuhan]. Clin J Dis Control Prev 5: 118-120 (in Chinese).

Ye J, Shi NF (2007) [Case control study on the risk factors of colorectal cancer in Cixi city of Zhejiang province]. Dis Surveillance 22: 196-198 (in Chinese).

Zhan W, Dierker LC, Rose JS, Selya A, Mermelstein RJ (2012) The natural course of nicotine dependence symptoms among adolescent smokers. Nicotine Tob Res 14: 1445-1452.

This work is published under the standard license to publish agreement. After 12 months the work will become freely available and the license terms will switch to a Creative Commons AttributionNonCommercial-Share Alike 3.0 Unported License. 